Supplement of Atmos. Chem. Phys., 18, 5321-5342, 2018

https://doi.org/10.5194/acp-18-5321-2018-supplement

(C) Author(s) 2018. This work is distributed under

the Creative Commons Attribution 4.0 License.

(c) (1)

Supplement of

\title{
The effect of South American biomass burning aerosol emissions on the regional climate
}

Gillian D. Thornhill et al.

Correspondence to: Gillian D. Thornhill (g.thornhill@ reading.ac.uk)

The copyright of individual parts of the supplement might differ from the CC BY 4.0 License. 


\section{Supplemental Material}

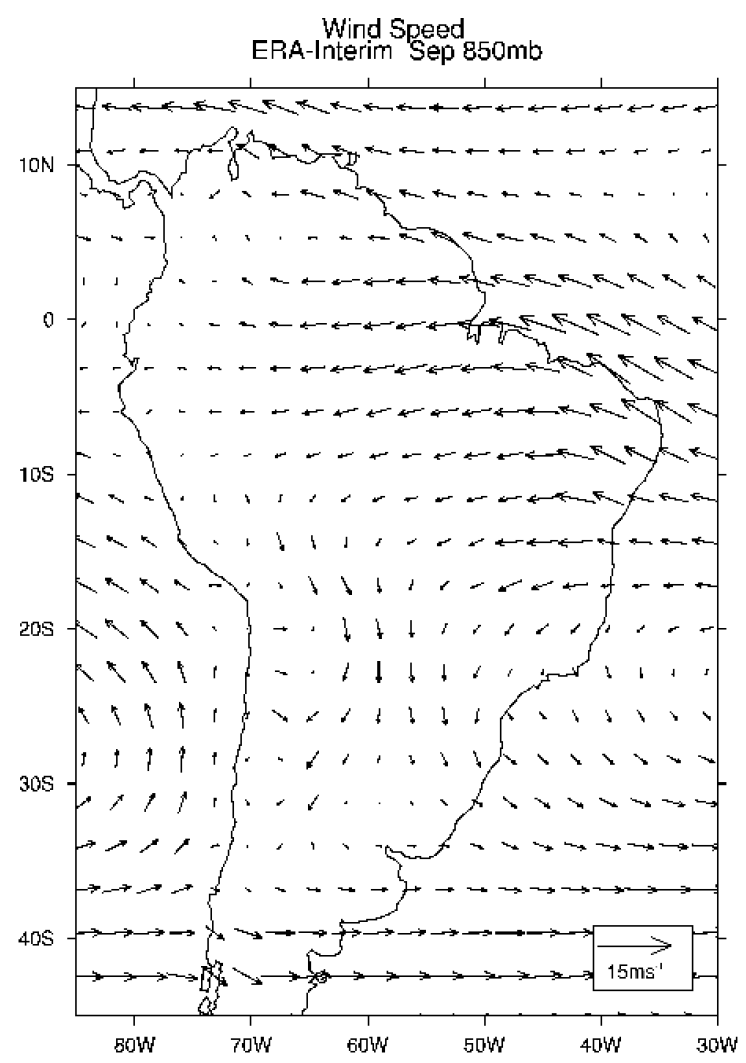

Figure S1. ERA-Interim September means over 1982-2012 for wind circulation at 850hPa.

The ERA-interim September means (1982-2012) generally compare well with the model results for the surface pressure and circulation, although we see some differences in cloud fraction between the model and ERA-Interim for the overall cloud cover. The model tends to slightly over-estimate cloud cover in some areas, but the general spatial pattern is similar bwteen the two.

5 The precipitation is also broadly similar, with some dicrepancies in the equatorial region, but over most of the region the values are generally similar. These comparisons are included here to demonstrate confidence in the model's ability to reproduce the broad elements of the meteorology for South America in September. 


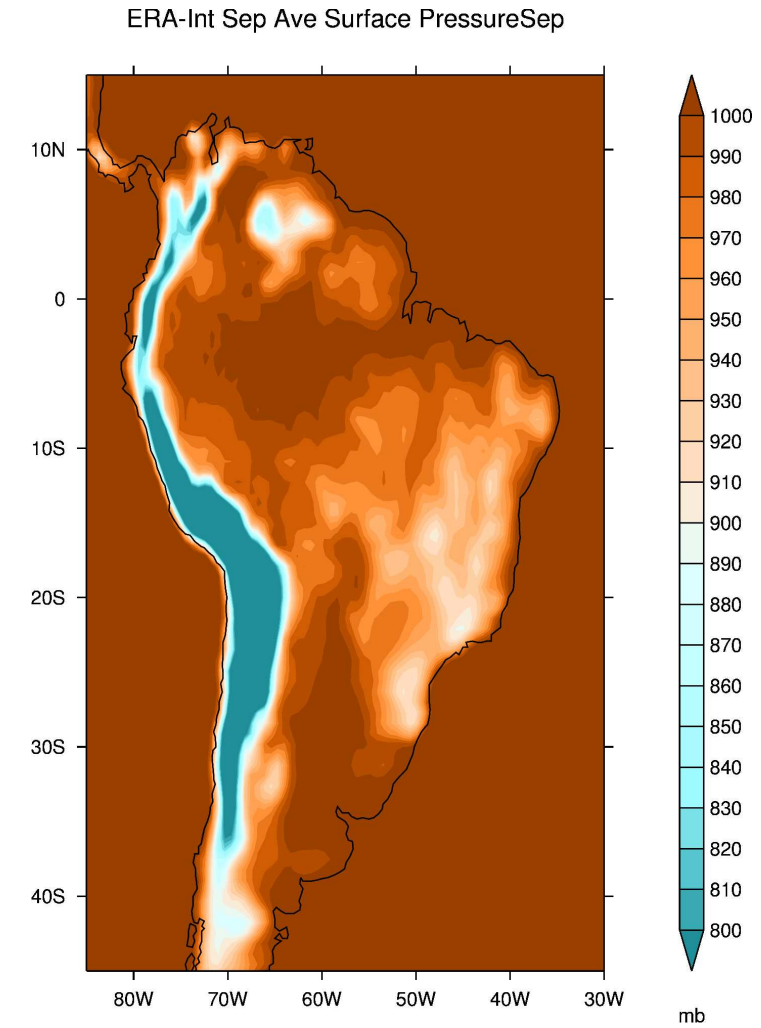

Figure S2. ERA-Interim September means over 1982-2012 for surface pressure in mb. 


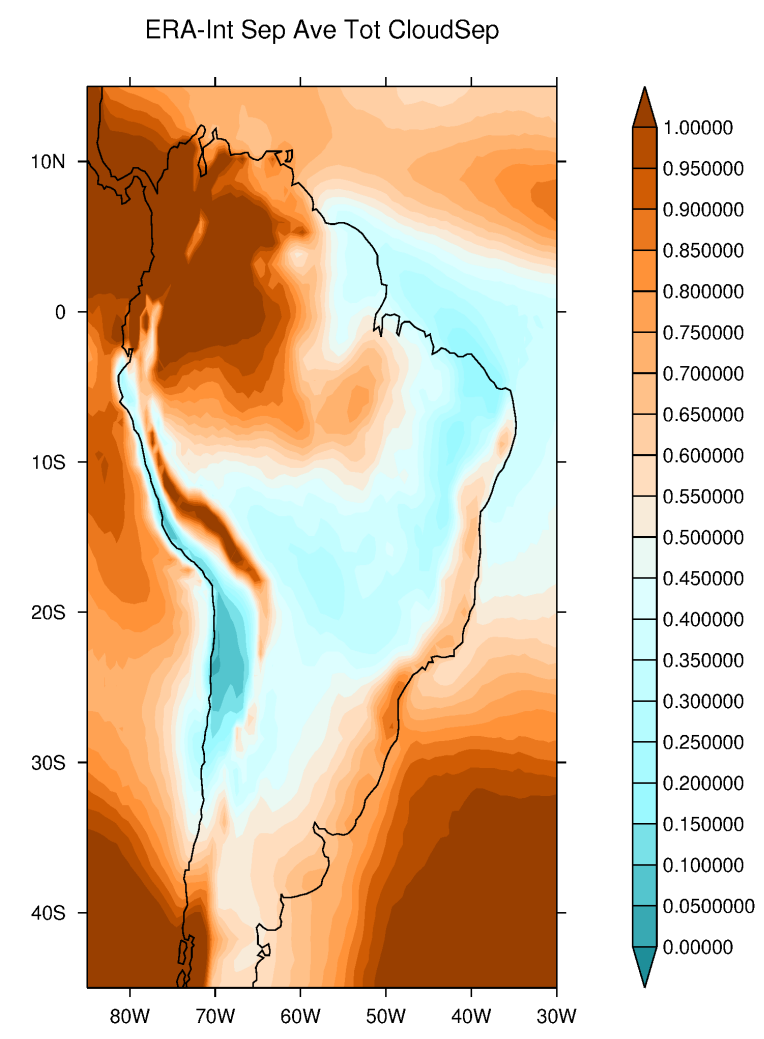

Figure S3. ERA-Interim September means over 1982-2012 for cloud fraction. 
ERA_INT Total RainSep

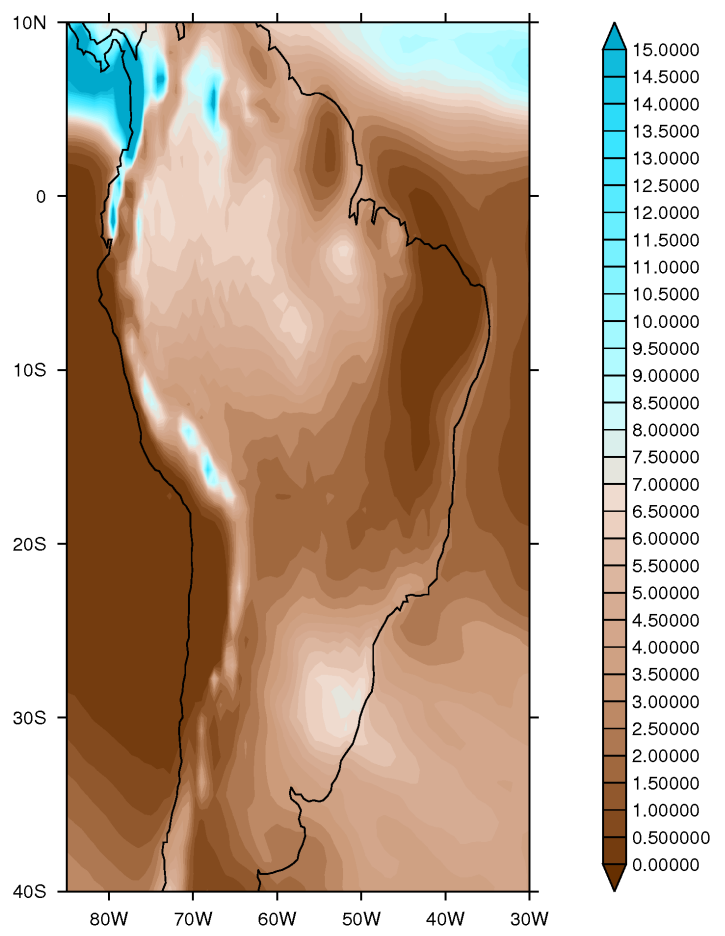

Figure S4. ERA-Interim September means over 1982-2012 for total precipitation. 


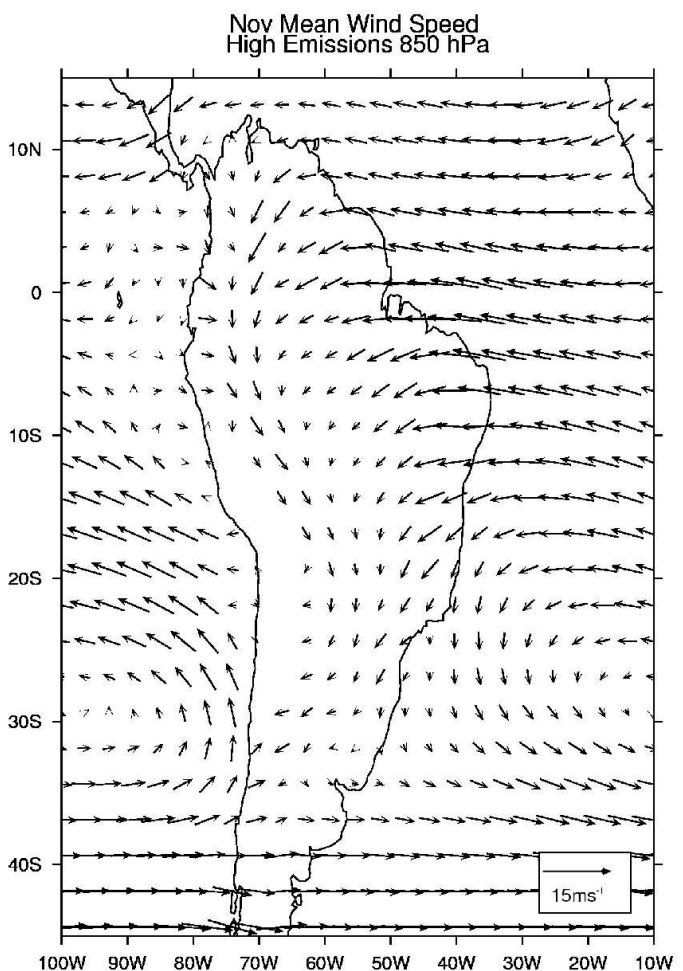

(a)

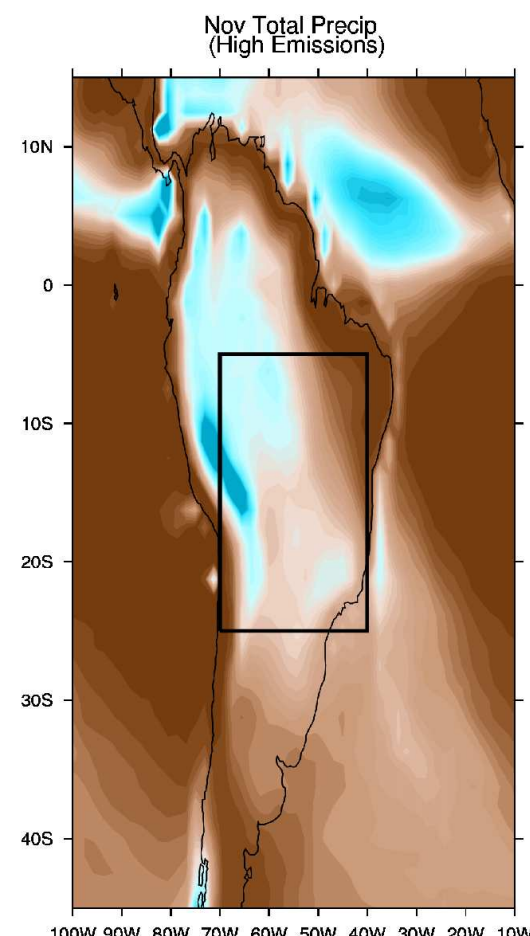

(c)

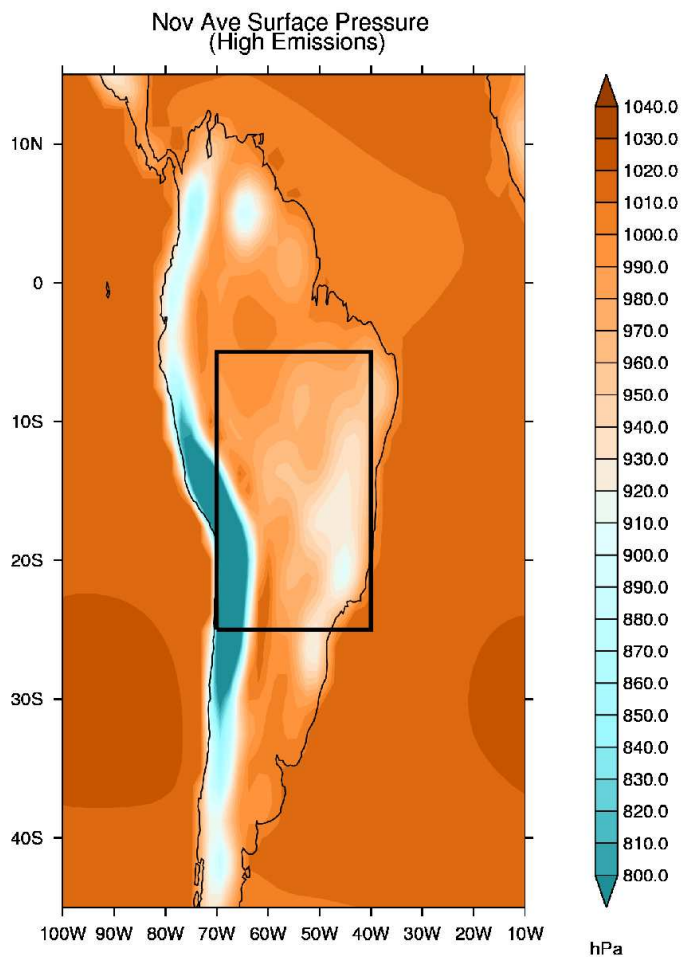

(b)

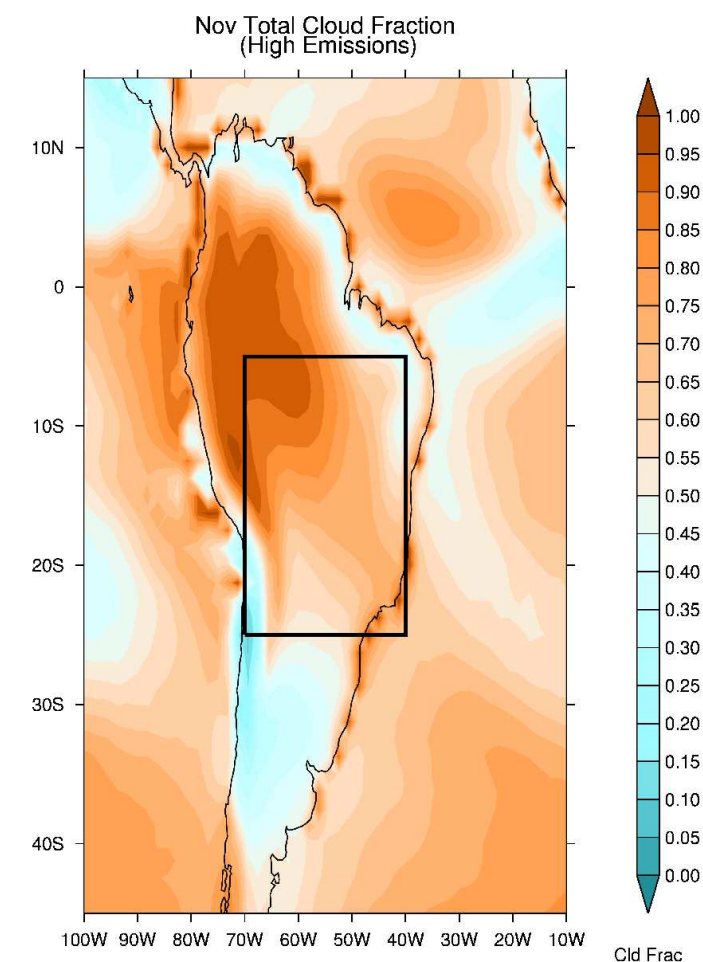

(d)

Figure S5. Mean monthly values for November high emissions case $\mathbf{5}$ ) Circulation at $850 \mathrm{hPa}$ (b) Surface pressure (hPa) (c) Precipitation (mm/day) (d) Cloud cover 